\title{
Management of floating thrombus in the aortic arch
}

Salome Weiss, MD, ${ }^{a}$ Roman Bühlmann, MD, ${ }^{a}$ Regula S. von Allmen, MD, ${ }^{b}$ Vladimir Makaloski, MD, ${ }^{a}$ Thierry P. Carrel, MD, ${ }^{\mathrm{a}}$ Jürg Schmidli, MD, ${ }^{\mathrm{a}}$ and Thomas R. Wyss, MD

\section{ABSTRACT}

Objective: Floating aortic thrombus is an underrecognized source of systemic emboli and carries a life-threatening risk of stroke when located in the aortic arch. Optimal treatment is not established in available guidelines. We report our experience in managing floating thrombi in the aortic arch.

Methods: Consecutive patients diagnosed with a floating aortic arch thrombus at a tertiary referral center between January 2008 and December 2014 were reviewed. Perioperative and midterm outcomes were assessed.

Results: Ten patients ( 8 female) with a median age of 56 years (range, 4782 years) were identified. Eight patients presented with a symptomatic embolic event, and 2 patients were asymptomatic. One patient presenting with stroke due to embolic occlusion of all supra-aortic vessels died 2 days after admission. Three patients ( 2 asymptomatic and 1 unfit for surgery) were treated conservatively by anticoagulation, leading to thrombus resolution in 2 patients. In the third patient, the thrombus persisted despite anticoagulation, resulting in recurrent embolic events. The remaining 6 patients underwent open thrombectomy of the aortic arch during deep hypothermic circulatory arrest. All patients treated by surgery had an uneventful postoperative course with no recurrent thrombus or embolic event during follow-up. Median follow-up of all patients was 17 months (range, 11-89 months).

Conclusions: Floating aortic arch thrombus is a dangerous source of systemic emboli. Surgical removal of the thrombus is easy to perform and followed by good clinical results. Conservative treatment with anticoagulation may be considered in asymptomatic, inoperable or high-risk patients. (J Thorac Cardiovasc Surg 2016;152:810-7)

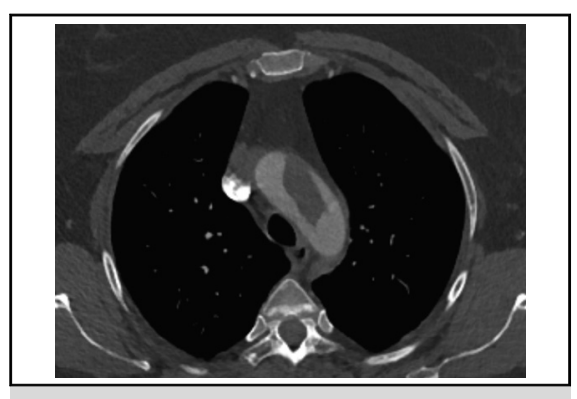

Floating aortic arch thrombus.

\section{Central Message}

Floating aortic arch thrombus is a dangerous source of emboli. Surgical removal of the thrombus is easy to perform and followed by good clinical results.

\section{Perspective}

Optimal treatment of floating aortic arch thrombus is not well established. Evidence concerning aortic arch thrombectomy for floating thrombi is scarce. With this study, we add a series of patients to the literature and demonstrate that aortic arch thrombectomy can be performed easily and with good clinical results in terms of prevention of further embolic events in these patients.

See Editorial Commentary page 818 .
Floating aortic thrombus is rare, but with the more frequent use of imaging modalities over the past decades, it has increasingly been identified as a source of systemic emboli. ${ }^{1}$ In a study of 10,671 consecutive autopsies, the incidence of aortic mural thrombus was $0.45 \% .^{2}$ The most common location reported in clinical studies ${ }^{3}$ is the descending thoracic aorta and the aortic arch. Detailed pathophysiologic mechanisms are not yet fully understood.

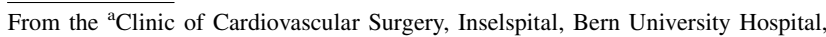
University of Bern, Bern; and ${ }^{\mathrm{b}}$ Clinic for Vascular Surgery, Kantonsspital St Gallen, St Gallen, Switzerland.

Received for publication Jan 11, 2016; revisions received March 20, 2016; accepted for publication March 28, 2016; available ahead of print May 6, 2016.

Address for reprints: Thomas R. Wyss, MD, Clinic of Cardiovascular Surgery, Inselspital, Bern University Hospital, University of Bern, 3010 Bern, Switzerland (E-mail: thomas.wyss@insel.ch).

$0022-5223 / \$ 36.00$

Copyright $(2) 2016$ by The American Association for Thoracic Surgery

http://dx.doi.org/10.1016/j.jtcvs.2016.03.078
Some authors reported mobile thrombi on aortic arch atheroma in predominantly elderly patients with atherosclerotic disease. ${ }^{4}$ However, floating aortic thrombus often is seen in relatively young patients without severe atherosclerosis, and many authors agree that it is a distinct clinical entity that has to be distinguished from atheromatous debris, ${ }^{1,3,5}$ although atherosclerotic processes may contribute to its pathogenesis. ${ }^{1}$ A high prevalence of hematologic disorders and other hypercoagulable conditions (eg, malignancy) has been reported in other series, suggesting these also may be causative factors for thrombus

Scanning this QR code will take you to a procedural video. 


\section{Abbreviations and Acronyms}
ASA $=$ acetylsalicylic acid
$\mathrm{CT}=$ computed tomography
DHCA $=$ deep hypothermic circulatory arrest
TEE $=$ transesophageal echocardiography

formation. ${ }^{3}$ Treatment options include anticoagulation, ${ }^{6,7}$ surgical thrombectomy, ${ }^{8-10}$ and, in some cases, endovascular treatment. ${ }^{11,12}$ However, comparative data are scarce, and available guidelines ${ }^{13}$ lack treatment recommendations.

Thrombus localization in the aortic arch is particularly challenging, because cerebral embolization is an impending risk with substantial morbidity and mortality. Surgical treatment of aortic arch thrombus requires extracorporeal circulation and circulatory arrest. It is unclear whether the benefits of open thrombus removal outweigh the perioperative risks of aortic arch surgery. For aortic arch atheroma (with or without mobile components), current stroke guidelines do not recommend surgical treatment to prevent cerebral embolization. ${ }^{14}$ This is based on a study by Stern and colleagues, ${ }^{15}$ who analyzed stroke risk during cardiac surgery in patients with arch atheroma and reported an unproportionally high incidence of intraoperative stroke $(34.9 \%)$ in patients who underwent arch endarterectomy in addition to another cardiac procedure.

The aim of this study was to assess detailed narrative data including risk factors, clinical presentation, treatment modality, and midterm outcome of patients with floating aortic arch thrombus. Our hypothesis was that surgical management has a favorable outcome and effectively prevents further embolic events in patients with floating aortic arch thrombus.

\section{MATERIALS AND METHODS}

Consecutive patients treated for floating aortic arch thrombus at a Swiss tertiary referral center (University Hospital Bern) between January 2008 and December 2014 were identified. Individual patient consent was obtained, and the study was performed according to the requirements of the local ethics committee.

Floating aortic arch thrombus was defined as a homogenous mass on computed tomography (CT) or transesophageal echocardiography (TEE) images, attached to the aortic wall and protruding into the lumen of the aortic arch with a mobile aspect (Figure 1). Information on size, exact localization, and quality of the attachment site of the thrombus was retrieved from contrast-enhanced CT scans (1-mm slice thickness). Data including patient demographics, cardiovascular and thrombotic risk factors, embolization site, treatment method, and postoperative complications were collected from hospital records. Patient follow-up included regular visits in our outpatient clinic and was completed by a telephone interview of all patients or their general practitioner at the end of June 2015 to assess for death, recurrent embolism, continuation of anticoagulation, and subsequently diagnosed malignant disease.

\section{RESULTS}

\section{Patient Characteristics and Clinical Presentation}

Over a period of 7 years, a total of 10 patients were identified. Eight patients were female, and the median age was 56 years (range, 47-82 years). All patients had 2 or more cardiovascular risk factors, mainly hypertension $(\mathrm{n}=8)$, smoking $(\mathrm{n}=7)$, or a body mass index $30 \mathrm{~kg} / \mathrm{m}^{2}$ or greater $(\mathrm{n}=7)$. Other previously described predisposing factors for aortic thrombus formation ${ }^{7}$ were steroids $(\mathrm{n}=2)$, hormone replacement therapy $(\mathrm{n}=1)$, and malignancy $(\mathrm{n}=1$, high-grade undifferentiated pleomorphic sarcoma of the pelvic bone). Two patients had a personal or a family history of venous thromboembolism. Thrombophilia testing was performed in 6 patients and revealed procoagulant abnormalities in 4 (Table 1). One patient had a patent foramen ovale. None had atrial fibrillation or any other identifiable embolic source. The diameter
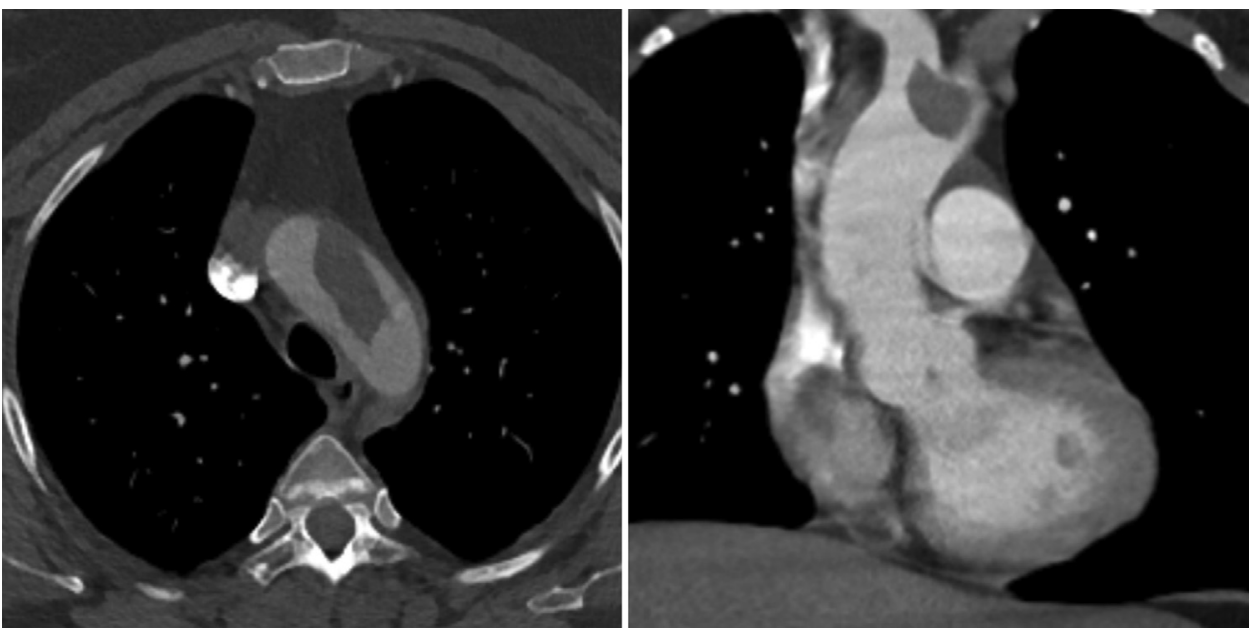

FIGURE 1. CT images of floating aortic arch thrombus (patient number 7). 
TABLE 1. Patient characteristics and risk factors

\begin{tabular}{|c|c|c|c|c|c|}
\hline Patient no. & Age (y) & Gender & Cardiovascular risk factors & Procoagulant abnormalities & Other predisposing factors \\
\hline 1 & 71 & $\mathrm{~F}$ & HT, obesity & $\begin{array}{l}\text { Hyperfibrinogenemia, elevated } \\
\text { factor VIII, mild } \\
\text { hyperhomocysteinemia }\end{array}$ & $\begin{array}{l}\text { Steroid therapy, personal history } \\
\text { of DVT }\end{array}$ \\
\hline 2 & 51 & F & HT, smoking, DL, obesity & $\begin{array}{l}\text { Only tested for lupus } \\
\text { anticoagulants (negative) }\end{array}$ & - \\
\hline 3 & 59 & $\mathrm{~F}$ & $\begin{array}{l}\text { Smoking, family history of } \\
\text { sudden cardiac death }\end{array}$ & $\begin{array}{l}\text { Mild hyperhomocysteinemia, } \\
\text { elevated von Willebrand } \\
\text { antigen }\end{array}$ & $\begin{array}{l}\text { Hormone replacement therapy, } \\
\text { family history of DVT }\end{array}$ \\
\hline 4 & 47 & M & HT, smoking, DL, obesity & Not tested & - \\
\hline 5 & 48 & $\mathrm{~F}$ & HT, smoking, DL, obesity & $\begin{array}{l}\text { Heterozygous factor V Leiden } \\
\text { mutation }\end{array}$ & - \\
\hline 6 & 77 & $\mathrm{~F}$ & HT, DL, obesity & $\begin{array}{l}\text { Heterozygous factor V Leiden } \\
\text { mutation, elevated factor XI }\end{array}$ & - \\
\hline 7 & 55 & $\mathrm{~F}$ & DM, HT, smoking, DL, obesity & Tested, no abnormalities & - \\
\hline 8 & 57 & $\mathrm{~F}$ & HT, smoking & Tested, no abnormalities & Steroid therapy \\
\hline 9 & 50 & M & Smoking, obesity & $\begin{array}{l}\text { Only tested for lupus } \\
\text { anticoagulants (negative) }\end{array}$ & $\begin{array}{l}\text { Malignant sarcoma, chronic } \\
\text { infection }\end{array}$ \\
\hline 10 & 82 & $\mathrm{~F}$ & HT, DL & Not tested & - \\
\hline
\end{tabular}

Obesity = body mass index $\geq 30 \mathrm{~kg} / \mathrm{m}^{2} . F$, Female; $H T$, hypertension; $D V T$, deep venous thrombosis; $D L$, dyslipidemia; $M$, male; $D M$, diabetes mellitus.

of the ascending aorta and aortic arch was normal in all patients. Thrombus developed under combined acetylsalicylic acid (ASA) and statin treatment in 2 patients (numbers 2 and 7), under ASA in 2 patients (numbers 9 and 10), and under statin therapy in 1 patient (number 6). No patients were on anticoagulation therapy at presentation.

Eight patients were diagnosed with floating aortic arch thrombus after a symptomatic embolic event, including upper- or lower-limb ischemia $(n=4)$, distal aortic occlusion $(\mathrm{n}=1)$, visceral ischemia $(\mathrm{n}=1)$, and ischemic stroke $(n=2)$ (Table 2). Of these patients, 6 were diagnosed by CT angiography and 2 were initially diagnosed by TEE. One patient (number 5) had 2 TEE examinations that did not demonstrate the thrombus, before it was diagnosed by CT angiography.

Two patients had no symptomatic embolic event at presentation (numbers 4 and 9). The thrombus was incidentally diagnosed by $\mathrm{CT}$, performed for acute chest pain or cancer staging.

\section{Thrombus Localization and Morphology}

Three patients (numbers 2, 8, and 9) had 2 thrombi localized in the aortic arch, resulting in a total of 13 thrombi in 10 patients. Median thrombus length measured on CT scans was $2.8 \mathrm{~cm}$ (range, 1.3-4.3 cm), and median width was $0.9 \mathrm{~cm}$ (range, 0.5-1.8 cm). No correlation between thrombus size and symptoms was observed.

The localization of the attachment sites is shown in Figure 2. On CT scans, the attachment site appeared to be normal aortic wall in 6 patients, whereas in 3 patients, there were minor calcified atherosclerotic changes. Only patient number 6 showed evidence of a heavily calcified plaque at the attachment site.

\section{Treatment}

In 6 patients (numbers 1, 2, 3, 6, 7, and 8), surgical embolectomy was required to treat the initial embolic event. Histologic examination of the embolus was performed in 5 patients and confirmed thrombus. Endovascular cerebral mechanical thrombectomy was performed in 2 patients with ischemic stroke (numbers 5 and 10). Patient number 10 , presenting with stroke due to embolic occlusion of all supra-aortic vessels, died 2 days after unsuccessful mechanical thrombectomy. For these 2 patients, no analysis of the removed embolic material was available.

In 3 patients, the floating aortic arch thrombus was treated conservatively using anticoagulation only, including 1 symptomatic patient aged 77 years (number 6) who was considered unfit for aortic arch surgery and 2 asymptomatic patients (numbers 4 and 9). The remaining 6 patients were scheduled for open aortic arch thrombectomy.

\section{Aortic Arch Thrombectomy}

Aortic arch thrombectomy was performed via median sternotomy using cardiopulmonary bypass and deep hypothermic circulatory arrest (DHCA). Arterial cannulation site for cardiopulmonary bypass was the right subclavian artery $(n=4)$ or the ascending aorta $(n=2)$, depending on thrombus localization. Median operating time was $180 \mathrm{mi}-$ nutes (range, 120-277 minutes), and median DHCA duration was 17 minutes (range, 12-42 minutes) with antegrade cerebral perfusion (median, 16 minutes; range, 11-42 minutes). In 1 patient with very short DHCA 
TABLE 2. Clinical data, treatment, and outcome

\begin{tabular}{|c|c|c|c|c|c|c|c|}
\hline Patient no. & $\begin{array}{l}\text { Initial embolic event/ } \\
\text { clinical presentation }\end{array}$ & $\begin{array}{c}\text { Evidence of } \\
\text { other embolism }\end{array}$ & $\begin{array}{l}\text { Thrombus } \\
\text { size }(\mathbf{c m})\end{array}$ & $\begin{array}{l}\text { Calcifications at } \\
\text { insertion site }\end{array}$ & $\begin{array}{l}\text { Treatment of aortic } \\
\text { arch thrombus }\end{array}$ & $\begin{array}{l}\text { Follow-up } \\
\quad(\mathrm{mo})\end{array}$ & $\begin{array}{l}\text { Outcome at the } \\
\text { end of follow-up }\end{array}$ \\
\hline 1 & $\begin{array}{l}\text { Left brachial artery/ } \\
\text { acute arm ischemia }\end{array}$ & - & $3.5 \times 1.7$ & None & $\begin{array}{l}\text { Thrombectomy } \\
\text { without resection of } \\
\text { attachment site }\end{array}$ & 89 & $\begin{array}{l}\text { Alive, no recurrent } \\
\text { embolism }\end{array}$ \\
\hline 2 & $\begin{array}{l}\text { Infrarenal aorta/ } \\
\text { paraplegia }\end{array}$ & $\begin{array}{l}\text { Preexisting PAD, } \\
\text { presumably } \\
\text { embolic }\end{array}$ & $\begin{array}{l}4.0 \times 1.1 \\
1.3 \times 0.6\end{array}$ & Minimal & $\begin{array}{l}\text { Thrombectomy } \\
\text { without resection of } \\
\text { attachment site }\end{array}$ & 83 & $\begin{array}{l}\text { Alive, no recurrent } \\
\text { embolism }\end{array}$ \\
\hline 3 & $\begin{array}{l}\text { Superior mesenteric } \\
\text { artery/bowel } \\
\text { ischemia }\end{array}$ & $\begin{array}{l}\text { Ischemic lesions in } \\
\text { spleen and kidneys } \\
\text { on CT, multiple } \\
\text { bihemispheric and } \\
\text { cerebellar } \\
\text { infarctions on MRI }\end{array}$ & $1.5 \times 0.5$ & None & $\begin{array}{l}\text { Thrombectomy with } \\
\text { resection of } \\
\text { attachment site }\end{array}$ & 58 & $\begin{array}{l}\text { Alive, no recurrent } \\
\text { embolism }\end{array}$ \\
\hline 4 & None & $\begin{array}{l}\text { Previous episode of } \\
\text { bilateral } \\
\text { scintillating } \\
\text { scotoma }\end{array}$ & $3.6 \times 1.4$ & None & $\begin{array}{l}\text { Conservative with AC } \\
\text { (phenprocoumon) }\end{array}$ & 29 & $\begin{array}{l}\text { Alive, resolution of } \\
\text { thrombus, } \\
\text { embolism (arm } \\
\text { ischemia) } 7 \text { mo } \\
\text { after AC was } \\
\text { stopped }\end{array}$ \\
\hline 5 & $\begin{array}{l}\text { Left middle and } \\
\text { anterior cerebral } \\
\text { artery/right } \\
\text { hemisyndrome, } \\
\text { aphasia (NIHSS 18) }\end{array}$ & $\begin{array}{l}\text { Right leg ischemia and } \\
\text { supposed TIA } \\
\text { before thrombus } \\
\text { could be treated }\end{array}$ & $3 \times 0.9$ & None & $\begin{array}{l}\text { Thrombectomy with } \\
\text { resection of } \\
\text { attachment site }\end{array}$ & 17 & $\begin{array}{l}\text { Alive, no recurrent } \\
\text { embolism }\end{array}$ \\
\hline 6 & $\begin{array}{l}\text { Left subclavian artery/ } \\
\text { acute arm ischemia }\end{array}$ & - & $1.6 \times 0.8$ & Yes & $\begin{array}{l}\text { Conservative with } \mathrm{AC} \\
\text { (phenprocoumon) }\end{array}$ & 17 & $\begin{array}{l}\text { Alive, resolution of } \\
\text { thrombus, no } \\
\text { recurrent embolism }\end{array}$ \\
\hline 7 & $\begin{array}{l}\text { Right femoral } \\
\text { bifurcation/acute } \\
\text { leg ischemia }\end{array}$ & - & $4.3 \times 1.8$ & None & $\begin{array}{l}\text { Thrombectomy with } \\
\text { resection of } \\
\text { attachment site }\end{array}$ & 13 & $\begin{array}{l}\text { Alive, no recurrent } \\
\text { embolism }\end{array}$ \\
\hline 8 & $\begin{array}{l}\text { Left subclavian and } \\
\text { brachial artery/ } \\
\text { subacute arm } \\
\text { ischemia }\end{array}$ & $\begin{array}{l}\text { Previous temporary } \\
\text { unilateral vision } \\
\text { loss; occlusion of } \\
\text { coeliac trunk on CT }\end{array}$ & $\begin{array}{l}2.4 \times 0.9 \\
1.8 \times 0.6\end{array}$ & None & $\begin{array}{l}\text { Thrombectomy with } \\
\text { resection of } \\
\text { attachment site }\end{array}$ & 11 & $\begin{array}{l}\text { Alive, no recurrent } \\
\text { embolism }\end{array}$ \\
\hline 9 & None & - & $\begin{array}{l}2.8 \times 0.8 \\
2.2 \times 0.7\end{array}$ & Minimal & $\begin{array}{l}\text { Conservative with } \mathrm{AC} \\
\text { (initially } \\
\text { phenprocoumon, } \\
\text { then LMWH) }\end{array}$ & 10 & $\begin{array}{l}\text { Ischemic stroke } \\
\text { (NIHSS 6) } 2 \mathrm{~d} \text { after } \\
\text { initiation of AC, } \\
\text { thereafter multiple } \\
\text { TIAs; died of } \\
\text { sarcoma after } 11 \mathrm{mo}\end{array}$ \\
\hline 10 & $\begin{array}{l}\text { Subtotal occlusion of } \\
\text { all supra-aortic } \\
\text { vessels/right } \\
\text { hemisyndrome, } \\
\text { aphasia (NIHSS 26) }\end{array}$ & Previous TIA & $3.4 \times 0.9$ & Minimal & $\begin{array}{l}\text { Died } 2 \mathrm{~d} \text { after } \\
\text { admission as the } \\
\text { result of initial } \\
\text { embolic event }\end{array}$ & - & - \\
\hline
\end{tabular}

PAD, Peripheral artery disease; $C T$, computed tomography; $M R I$, magnetic resonance imaging; $A C$, anticoagulation; NIHSS, National Institutes of Health Stroke Scale; TIA, transient ischemic attack; $L M W H$, low-molecular-weight heparin.

(12 minutes), antegrade cerebral perfusion was not performed. During opening, preparation for cardiopulmonary bypass and cannulation, the thrombus was monitored by TEE. After incision of the aortic arch, the thrombus was completely removed in all patients (Figure 3). The aortic wall at the attachment site was resected in 4 patients (fullthickness wall resection), whereas the aortic wall seemed macroscopically normal in 2 patients. Aortotomy and the resection site in case of attachment site resection were directly closed by double-layer 4-0 polypropylene running sutures in all patients. No prosthetic material was used, neither as a vascular graft nor as a patch (Video 1).

Histologic examination confirmed that the removed material was a thrombus in all patients. Microscopically, the attachment site was unremarkable in 1 patient while showing a cholesterol-rich plaque in 3 patients. 


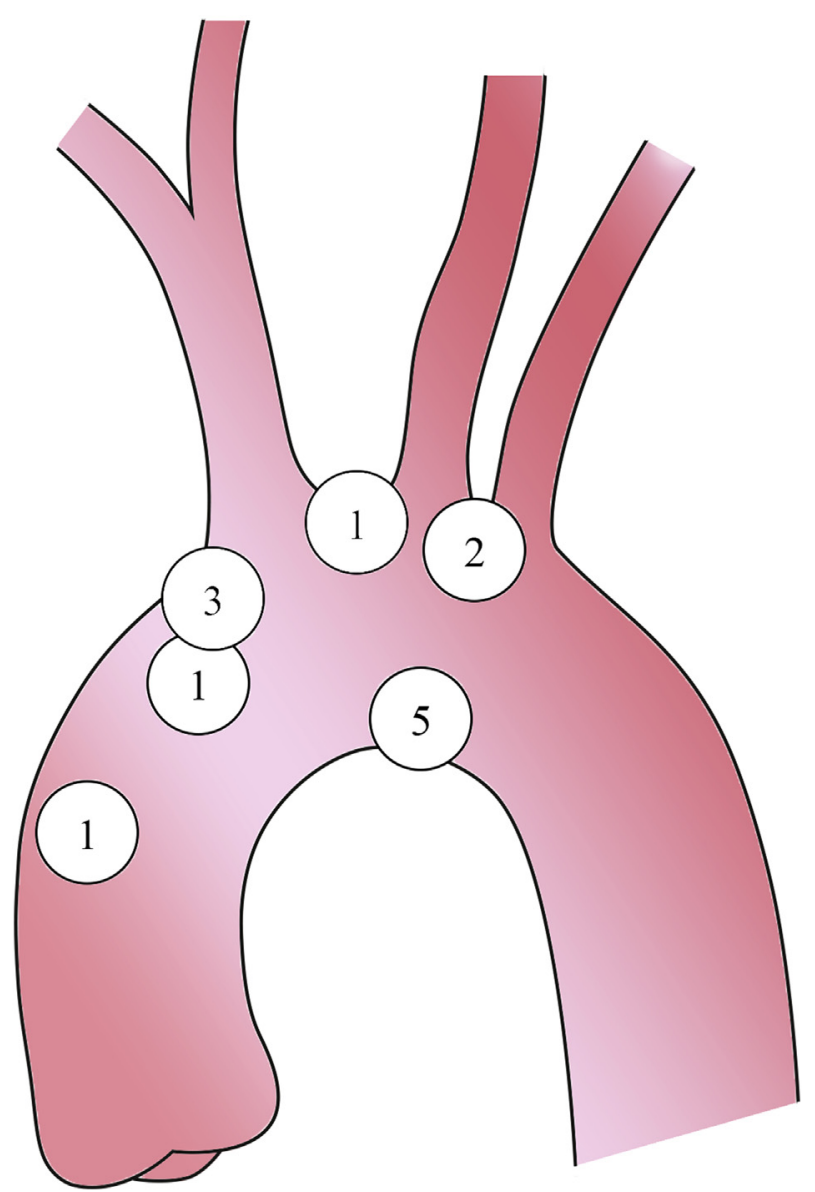

FIGURE 2. Attachment sites of 13 thrombi in 10 patients ( 2 concurrent thrombi in 3 patients).

\section{Follow-up}

Median follow-up was 17 months (range, 11-89 months). At the end of follow-up, 8 of 10 patients were alive. Patient number 10 died in the context of the initial embolic event, and patient number 9 died 11 months after diagnosis of the aortic arch thrombus due to the underlying malignant disease. In all other patients, no malignant disease as a potential causative factor for thrombus formation was diagnosed during follow-up.

Conservative treatment. In patient number 4, asymptomatic at presentation, follow-up CT confirmed complete resolution of the thrombus, leading to discontinuation of oral anticoagulation after 3 months. Seven months later, the patient presented with embolic occlusion of the forearm arteries, requiring embolectomy. Histologic examination of the removed material confirmed thrombus, but no recurrent thrombus in the aortic arch or other embolic source could be identified. Under resumed anticoagulation, the patient experienced no further embolic events.

The elderly, symptomatic patient (number 6), considered unfit for open aortic arch surgery, had complete resolution of the thrombus after 3 months (follow-up CT) and no recurrent embolism under continued anticoagulation at the end of follow-up.

The patient with malignant sarcoma (number 9), asymptomatic at diagnosis of the aortic arch thrombus, had an ischemic stroke 2 days after initiation of anticoagulation and underwent intravenous thrombolytic therapy. Thrombus formation in the aortic arch remained unchanged on follow-up CT scans. Because of progressive malignant disease, this patient was not considered a candidate for surgical thrombectomy. Despite continued anticoagulation (low-molecular-weight heparin), the patient had multiple transient ischemic attacks and died 11 months later as a consequence of the malignancy.

Surgical treatment. All 6 patients treated by open aortic arch thrombectomy had an uneventful postoperative course. No ischemic stroke, myocardial infarction, significant deterioration of renal function, postoperative hemorrhage, or sternal infection was documented. Postoperatively, 5 patients received oral anticoagulation treatment with coumarin. Patient number 5 , initially presenting with stroke, received no anticoagulation because of hemorrhagic transformation of the cerebral infarction. Patient number 3 was prescribed dual antiplatelet therapy (ASA and clopidogrel) at discharge because therapeutic anticoagulation doses could not be established with coumarin. Coumarin was switched to clopidogrel 28 months after surgery in patient number 2 . Three patients were still taking coumarin at the end of follow-up. There were no recurrent embolic events or recurrent aortic thrombi in these surgically treated patients.

\section{DISCUSSION}

In this study, we present a consecutive series of $10 \mathrm{pa}-$ tients with floating thrombus in the aortic arch, 6 of whom were treated by open aortic arch thrombectomy. The median age of our patients was slightly higher than reported in other series. ${ }^{1,3,16}$ Female predominance has been reported. ${ }^{5,17}$ Mild procoagulant abnormalities were present in $40 \%$ of patients, and in 1 patient, the cause of the thrombus was most likely paraneoplastic, but overall, there was a high prevalence of cardiovascular risk factors. Nevertheless, only 1 patient had a relevant atherosclerotic lesion at the thrombus attachment site confirmed by $\mathrm{CT}$, whereas in all other patients, the aortic wall appeared normal or with minimal calcifications on CT scans. Histologic examination of the attachment sites resected along with the thrombus showed a cholesterol-rich plaque in 3 of 4 patients. These findings suggest that atherosclerosis does contribute to the pathogenesis of floating aortic thrombi but may not be apparent as calcified plaque. The degree of atherosclerotic contribution may differ between patients and other factors; for example, hematologic abnormalities and steroid treatment may facilitate thrombus formation. 


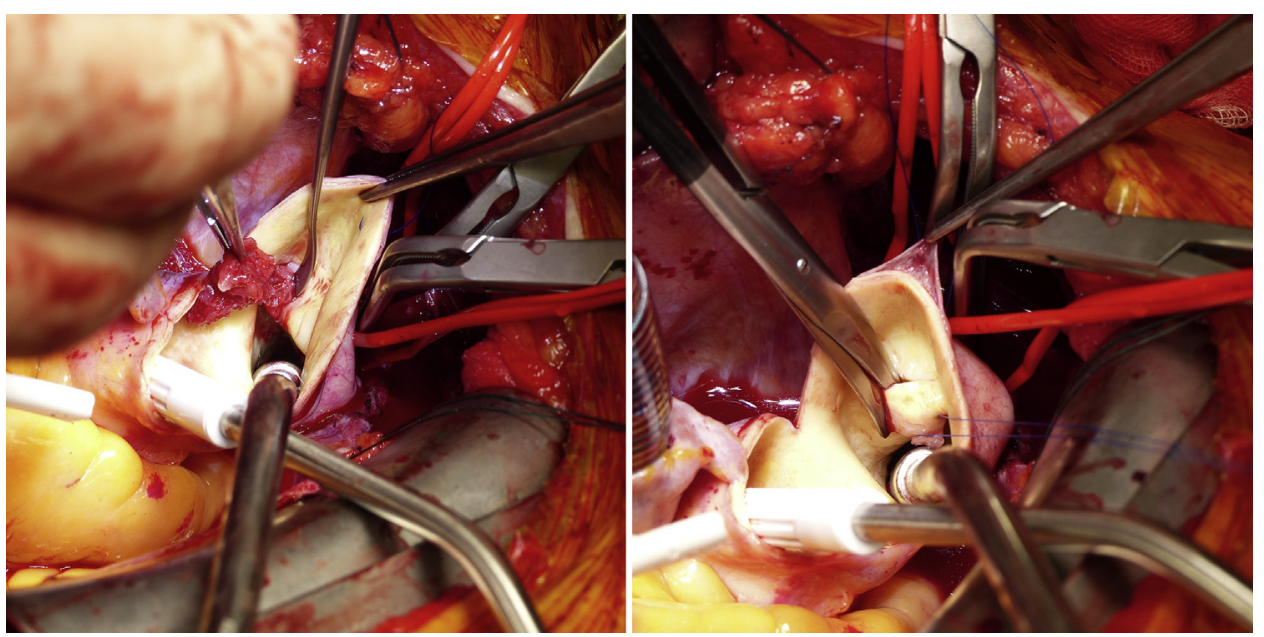

FIGURE 3. Intraoperative images (patient number 5): view into the proximal aortic arch. The thrombus is removed by means of a dissector (left). The aortic wall at the attachment site is fixed with a thread and completely cut out (right).

TEE is considered the technique of choice to detect and characterize thoracic aortic lesions, such as intramural hemorrhage, dissection, and atherosclerosis. ${ }^{18,19}$ However, visualization of a short segment of the most cranial ascending aorta proximally to the origin of the innominate artery is limited in TEE. ${ }^{18}$ In our series, 1 patient underwent 2 TEE examinations with no pathologic findings before aortic arch thrombus was diagnosed by CT. Therefore, especially if no other embolic source is found, diagnostic workup of patients with cerebral, visceral, or peripheral emboli should be completed by CT angiography of the whole aorta. Even if a cardiac source of embolism is found, CT angiography should be used liberally to exclude a concomitant aortic embolic source with possible therapeutic consequences.

Emboli from floating aortic thrombi may cause relevant morbidity and mortality. In our series, 1 patient had acute Leriche syndrome with complete paraplegia, 1 patient had intestinal ischemia, and 2 patients had extensive ischemic strokes, with 1 patient dying of the immediate sequelae. Only 2 patients (numbers 4 and 9) were initially asymptomatic. Because diagnosis of floating aortic thrombus usually is made after an embolic event, there are few published reports including asymptomatic patients..$^{12,20,21}$ Therefore, little is known about the risk of these patients to have a first-time embolic event, with or without anticoagulation. In a previous autopsy study, $17 \%$ of patients with a thrombus in the thoracic or abdominal aorta had evidence of distal embolization, whereas $6 \%$ had evidence of a major embolic event that was considered the cause of death. ${ }^{2}$

In primarily symptomatic patients, a previous study reported recurrent embolism in 4 of 23 patients with floating arch thrombus despite intravenous heparin therapy. ${ }^{1}$ In a systematic review including 200 patients with aortic mural thrombus in all locations, 3 important predictors of recurrent arterial embolization were identified: thrombus location in the ascending aorta or arch, mild atherosclerosis of the aortic wall, and stroke as a presenting symptom. ${ }^{3}$ In our series, 6 of 8 patients who presented with an embolic event had radiologic evidence or a history of previous, possible embolic events, and 1 patient had another clinically evident embolism (limb ischemia) before the aortic arch thrombus was removed (Table 2). We considered these findings as indicators of a high risk of further recurrence, and thus these patients were treated surgically if no relevant contraindications were present.

In our series, no postoperative complications after aortic arch thrombectomy were documented. DHCA time was short, and intraoperative TEE monitoring provided additional assurance that thrombotic material did not dislocate during manipulations on the aortic arch or cannulation. Thrombus dislocation would have been detected immediately and would have prompted CT angiography for localization and subsequent treatment of the embolus with no delay. Although the risk of aortic arch surgery, especially cerebral embolization, cannot be denied, we believe that with necessary precautions and adequate patient selection, aortic arch thrombectomy can be performed with a high degree of safety and efficiency regarding prevention of further embolic events. Therefore, floating aortic arch thrombus should be distinguished from aortic arch atheroma or debris, the latter carrying a much higher perioperative risk if surgically removed. ${ }^{15}$

Patient number 9, treated by anticoagulation, had an ischemic stroke 2 days after anticoagulation was initiated. It remains unclear whether this was a coincidence. It has been postulated before that anticoagulation could trigger further embolic events by lysing the thrombus at a thin attachment site before lysing the thrombus itself. ${ }^{9}$ However, it has to be considered that this patient had underlying 


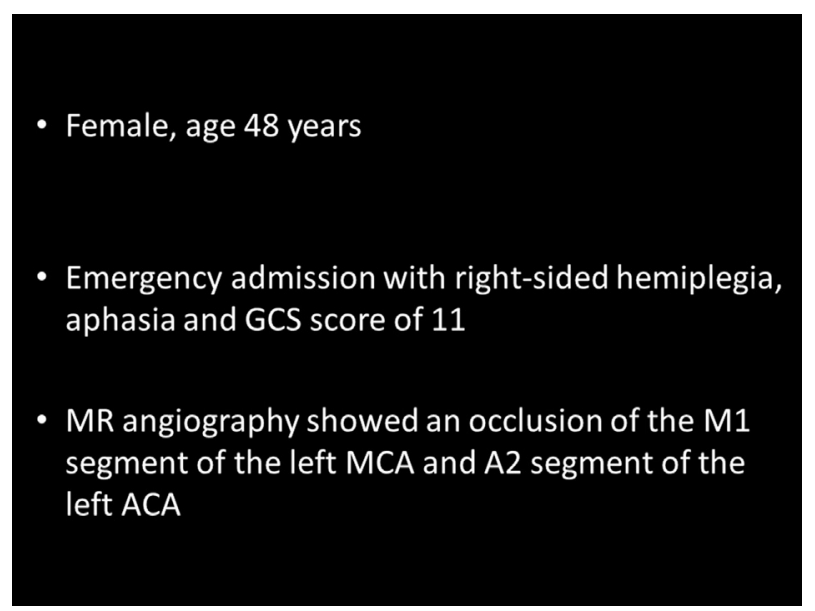

VIDEO 1. Removal of floating thrombus in the proximal aortic arch. Video available at http://www.jtcvsonline.org/article/S0022-5223(16) 30101-5/addons.

malignant disease, and therefore comparison with patients without malignancy is difficult.

Patient number 4, in whom anticoagulation was stopped after the thrombus resolved, later had an embolic event, whereas no recurrent aortic thrombus or other embolic source was found. The cause of this embolism remains unclear. It may be hypothesized that a new thrombus had formed at the old attachment site and embolized entirely. Local recurrence of a thrombus at the same site has been described in another series. ${ }^{1}$ In surgically treated patients, resection of the attachment site along with the thrombus should be considered. Resection of the attachment site was not associated with any complications in our series.

Procoagulant abnormalities seem to be prevalent in patients with floating aortic thrombi, which emphasizes the importance of hematologic workup. However, there are no available recommendations on anticoagulation and antiplatelet therapy in patients with floating aortic thrombus. Because atherosclerotic processes may contribute to the pathogenesis of floating aortic thrombi, secondary cardiovascular prevention including lifelong ASA and a statin is probably indicated in all patients, but there is no evidence.

\section{Study Limitations}

The main limitation of this study is its retrospective character. Because floating aortic arch thrombus is rare, there was no standard protocol in our clinic for such patients, and testing for procoagulant abnormalities was not performed routinely. Asymptomatic patients with floating aortic arch thrombus may be underrepresented in this study, because they are less likely referred to our service.

\section{CONCLUSIONS}

Floating aortic arch thrombus is an underrecognized but dangerous source of cerebral, visceral, and peripheral emboli and may cause significant morbidity and mortality. Especially if no other source of emboli is found, diagnostic workup of patients with systemic emboli by $\mathrm{CT}$ angiography is mandatory. Symptomatic patients with floating aortic arch thrombus should be considered at high risk for recurrent embolism, and therefore we advocate open thrombus removal with resection of the attachment site. Conservative treatment with anticoagulation only may be considered in selected cases, for example, high-risk and older patients with contraindications for surgery, as well as in asymptomatic patients.

\section{Conflict of Interest Statement}

Authors have nothing to disclose with regard to commercial support.

\section{References}

1. Laperche T, Laurian C, Roudaut R, Steg PG. Mobile thromboses of the aortic arch without aortic debris. A transesophageal echocardiographic finding associated with unexplained arterial embolism. The Filiale Echocardiographie de la Societe Francaise de Cardiologie. Circulation. 1997;96:288-94.

2. Machleder HI, Takiff H, Lois JF, Holburt E. Aortic mural thrombus: an occult source of arterial thromboembolism. J Vasc Surg. 1986;4:473-8.

3. Fayad ZY, Semaan E, Fahoum B, Briggs M, Tortolani A, D’Ayala M. Aortic mural thrombus in the normal or minimally atherosclerotic aorta. Ann Vasc Surg. 2013;27:282-90

4. Zavala JA, Amarrenco P, Davis SM, Jones EF, Young D, Macleod MR, et al. Aortic arch atheroma. Int J Stroke. 2006;1:74-80.

5. Tsilimparis N, Hanack U, Pisimisis G, Yousefi S, Wintzer C, Ruckert RI. Thrombus in the non-aneurysmal, non-atherosclerotic descending thoracic aorta-an unusual source of arterial embolism. Eur J Vasc Endovasc Surg. 2011;41:450-7.

6. Stollberger C, Kopsa W, Finsterer J. Resolution of an aortic thrombus under anticoagulant therapy. Eur J Cardiovasc Surg. 2001;20:880-2.

7. Bowdish ME, Weaver FA, Liebman HA, Rowe VL, Hood DB. Anticoagulation is an effective treatment for aortic mural thrombi. J Vasc Surg. 2002;36:713-9.

8. Goueffic Y, Chaillou P, Pillet JC, Duveau D, Patra P. Surgical treatment of nonaneurysmal aortic arch lesions in patients with systemic embolization. $J$ Vasc Surg. 2002;36:1186-93.

9. Geha AS, El-Zein C, Massad MG, Bagai J, Khoury F, Evans A, et al. Surgery for aortic arch thrombosis. Thorac Cardiovasc Surg. 2004;52:187-90.

10. Calderon P, Heredero A, Pastor A, Higueras J, Hernandez J, Karagounis PA, et al. Successful removal of a floating thrombus in ascending aorta. Ann Thorac Surg. 2011;91:e67-9.

11. Rancic Z, Pfammatter T, Lachat M, Frauenfelder T, Veith FJ, Mayer D. Floating aortic arch thrombus involving the supraaortic trunks: successful treatment with supra-aortic debranching and antegrade endograft implantation. J Vasc Surg. 2009;50:1177-80

12. Boufi M, Mameli A, Compes P, Hartung O, Alimi YS. Elective stent-graft treatment for the management of thoracic aorta mural thrombus. Eur J Vasc Endovasc Surg. 2014;47:335-41.

13. Erbel R, Aboyans V, Boileau C, Bossone E, Bartolomeo RD, Eggebrecht H, et al. 2014 ESC Guidelines on the diagnosis and treatment of aortic diseases: document covering acute and chronic aortic diseases of the thoracic and abdominal aorta of the adult. The Task Force for the Diagnosis and Treatment of Aortic Diseases of the European Society of Cardiology (ESC). Eur Heart J. 2014;35:2873-926.

14. Kernan WN, Ovbiagele B, Black HR, Bravata DM, Chimowitz MI, Ezekowitz MD, et al. Guidelines for the prevention of stroke in patients with stroke and transient ischemic attack: a guideline for healthcare professionals from the American Heart Association/American Stroke Association. Stroke. 2014;45:2160-236.

15. Stern A, Tunick PA, Culliford AT, Lachmann J, Baumann FG, Kanchuger MS, et al. Protruding aortic arch atheromas: risk of stroke during heart surgery with and without aortic arch endarterectomy. Am Heart J. 1999;138(4 Pt 1):746-52.

16. Choukroun EM, Labrousse LM, Madonna FP, Deville C. Mobile thrombus of the thoracic aorta: diagnosis and treatment in 9 cases. Ann Vasc Surg. 2002;16: 714-22.

17. Pagni S, Trivedi J, Ganzel BL, Williams M, Kapoor N, Ross C, et al. Thoracic aortic mobile thrombus: is there a role for early surgical intervention? Ann Thorac Surg. 2011;91:1875-81. 
18. Evangelista A, Flachskampf FA, Erbel R, Antonini-Canterin F, Vlachopoulos C, Rocchi G, et al. Echocardiography in aortic diseases: EAE recommendations for clinical practice. Eur J Echocardiogr. 2010;11:645-58.

19. Avegliano G, Evangelista A, Elorz C, Gonzalez-Alujas T, Garcia del Castillo H, Soler-Soler J. Acute peripheral arterial ischemia and suspected aortic dissection: usefulness of transesophageal echocardiography in differential diagnosis with aortic thrombosis. Am J Cardiol. 2002;90:674-7.
20. Chatterjee S, Eagle SS, Adler DH, Byrne JG. Incidental discovery of an ascending aortic thrombus: should this patient undergo surgical intervention? J Thorac Cardiovasc Surg. 2010;140:e14-6.

21. Hahn TL, Dalsing MC, Sawchuk AP, Cikrit DF, Lalka SG. Primary aortic mural thrombus: presentation and treatment. Ann Vasc Surg. 1999;13:52-9.

Key Words: aortic arch, embolism, thrombus

Readers who found these articles interesting may also like to read the following papers found in recent and future issues of our sister publications, Seminars in Thoracic and Cardiovascular Surgery and Operative Techniques in Thoracic and Cardiovascular Surgery!

\section{Acquired: Aortic Disease}

Original Submission: Outcomes of Open Surgical Repair for Type B Dissecting Aortic Aneurysm with Alternative Methods in the Endovascular Stent Era. Mitsumasa Hata. Semin Thorac Cardiovasc Surg 2015; Summer; 27(2):106-112.

Editorial Commentary: It is Difficult to Compare Apples and Oranges: Acute and Chronic Type B Aortic Dissections, Complicated and Uncomplicated, are Different and Should be Treated as Such. Ourania Preventza. Semin Thorac Cardiovasc Surg 2015; Summer; 27(2):113-114.

News and Views: Treatment of Thoracic Aortic Aneurysm: Role of Earlier Intervention. Bulat A. Ziganshin. Semin Thorac Cardiovasc Surg 2015; Summer; 27(2);135-143.

Aortic root enlargement during aortic valve replacement: Nicks and Manouguian techniques. Kendra J Grub. Oper Tech Thorac Cardiovasc Surg 2015; Autumn; 20(3):206-218.

The Konno-Rastan procedure for anterior aortic annular enlargement. Mark E. Roeser. Oper Tech Thorac Cardiovasc Surg 2015: Autumn; 20(3):219-233. 